\title{
CAPITAL DE RELACIONAMENTO E OBJETIVOS ESTRATÉGICOS: ANÁLISE DE UM PERIÓDICO DE ENFERMAGEM ${ }^{1}$
}

\section{Artig}

Ida Mara Brunelli da Silveira ${ }^{2}$

Raquel Borba Balceiro ${ }^{3}$

Isabel Amélia Costa Mendes ${ }^{4}$

Silveira IMB, Balceiro RB, Mendes IAC. Capital de relacionamento e objetivos estratégicos: análise de um periódico de enfermagem. Rev Latinoam Enfermagem 2005 março-abril; 13(2):195-202.

Trata-se de um estudo descritivo sobre a contribuição da Revista Latino-Americana de Enfermagem para a integração de enfermeiros do Brasil e da América Latina e para a fundamentação de suas ações profissionais. A metodologia está alicerçada no modelo de gestão do conhecimento denominado "Capitais do Conhecimento", desenvolvido pelo CRIE, com foco voltado para o Capital de Relacionamento assinantes. As informações foram obtidas no banco de assinantes da Revista e através de questionário eletrônico enviado aos 550 assinantes categorizados como "pessoa física" e portadores de endereço eletrônico obtendo-se resposta de 122. Verificou-se que a penetração da Revista é iniciante naAmérica Latina e satisfatória no Brasil. A contribuição da Revista para a fundamentação das ações profissionais do enfermeiro foi confirmada pelos respondentes.

DESCRITORES: publicações periódicas; enfermagem; conhecimento

\section{THE CONTRIBUTION OF A SCIENTIFIC JOURNAL TO NURSING INTEGRATION AND THE FOUNDATION OF PROFESSIONAL ACTIONS}

This study analyzes how the Latin American Journal of Nursing contributed to the integration of nurses in Brazil and Latin America and provided foundations for their professional actions. The research methodology is based on the knowledge management model called "Knowledge Capitals", developed by the CRIE (Business Intelligence Reference Center), which focuses on subscriber Relationship Capital. Data were collected from the Journal's subscriber database and by means of an electronic questionnaire sent to subscribers ranked as "private persons" and those with an electronic address. It was evidenced that the Journal's role is inexpressive in Latin America, with a merely satisfactory penetration in Brazil. The respondents confirmed the Journal's contribution to the foundation of professional nursing actions.

DESCRIPTORS: periodicals; nursing; knowledge

\section{LA CONTRIBUCIÓN DE UNA PUBLICACIÓN CIENTÍFICA PARA LA INTEGRACIÓN DE ENFERMEROS Y LA FUNDAMENTACIÓN DE ACCIONES PROFESIONALES}

Este estudio trata de la contribución de la Revista Latinoamericana de Enfermería a la integración de enfermeros de Brasil y América Latina y a la fundamentación de sus acciones profesionales. La metodología está basada en el modelo de gestión del conocimiento denominado "Capitales del Conocimiento", desarrollado por el CRIE (Centro de Referencia en Inteligencia Empresarial), con enfoque en el Capital de Relacionamiento - abonados. Las informaciones fueron obtenidas en el banco de abonados de la Revista y a través de un cuestionario electrónico enviado a los abonados categorizados como "persona física" y propietarios de dirección electrónica. Se concluye que la penetración de la Revista en América Latina es inexpresiva y, en Brasil, es sólo satisfactoria. Los respondientes confirmaron la contribución de la Revista a la fundamentación de las acciones profesionales del enfermero.

DESCRIPTORES: publicaciones periódicas; enfermería; conocimiento

\footnotetext{
${ }^{1}$ Trabalho extraído do projeto final de curso de especialização apresentado ao Programa de Pós-Graduação em Engenharia da Universidade Federal do Rio de Janeiro, 2003; ${ }^{2}$ Especialista em Gestão do Conhecimento e Inteligência Empresarial, Assistente Técnica Acadêmica da Escola de Enfermagem de Ribeirão Preto, da Universidade de São Paulo, Centro Colaborador da OMS para o desenvolvimento da pesquisa em enfermagem, Bolsista de Apoio Técnico do CNPq, sob responsabilidade da Profa ${ }^{2}{ }^{a}$ Isabel Amélia Costa Mendes, e-mail: idamara@eerp.usp.br; ${ }^{3}$ Doutor em Engenharia de Produção, Administradora Plena, Petróleo Brasileiro S.A., e-mail: rbalceiro@petrobras.com.br; ${ }^{4}$ Enfermeira, Pesquisador 1 A do CNPq, Professor Titular, Diretora da Escola de Enfermagem de Ribeirão Preto, da Universidade de São Paulo, Centro Colaborador da OMS para o desenvolvimento da pesquisa em enfermagem, e-mail: iamendes@eerp.usp.br
} 


\section{INTRODUÇÃO}

O conhecimento vem sendo a grande alavanca do desenvolvimento da humanidade, desde os seus primórdios. Agestão do conhecimento remonta às primeiras civilizações e, modernamente, significa o "esforço para fazer com que o conhecimento de uma organização esteja disponível para aqueles que dele necessitem dentro dela, quando isso se faça necessário, com o objetivo de aumentar 0 desempenho humano e organizacional' ${ }^{\prime(1)}$.

No momento atual, o que torna o uso do conhecimento diferenciado ${ }^{(2)}$ é a intensidade, a velocidade e a abrangência com as quais as informações são disseminadas e utilizadas, produzindo novos conhecimentos.

A gestão pró-ativa do conhecimento adquire papel central nessa nova ordem econômica, promovendo mudanças na estrutura das organizações, na gestão de recursos humanos e nas relações com os clientes, fornecedores e outros parceiros.

Este estudo está alicerçado no modelo de gestão do conhecimento denominado "Capitais do Conhecimento"(3), desenvolvido pelo Centro de Referência em Inteligência Empresarial (CRIE), laboratório associado ao Programa de Engenharia de Produção da Coordenação dos Programas de Pós-Graduação em Engenharia da Universidade Federal do Rio de Janeiro.

Tal modelo é composto pelos capitais intelectual, estrutural, de relacionamento e ambiental, que devem ser monitorados e gerenciados para a efetiva gestão do conhecimento de uma organização.

O Capital Estrutural compreende a infra-estrutura necessária ao funcionamento da organização, aí inclusos os sistemas administrativos, conceitos, modelos, rotinas, marcas, patentes, programas de computador e a cultural organizacional. O Capital Intelectual é um ativo intangível e pertencente ao indivíduo. Refere-se à capacidade, à habilidade e à experiência quanto ao conhecimento formal das pessoas que integram a organização. O Capital de Relacionamento é formado pela rede de relacionamentos de uma organização com clientes, fornecedores e parceiros, podendo ser individual ou institucional. O Capital Ambiental é o conjunto de fatores que descrevem o ambiente onde a organização está inserida.

Sabe-se que o Capital de Relacionamento pode favorecer importante retorno para o negócio. Contudo, dentre os Capitais do Conhecimento, é o que em geral apresenta maior descompasso entre sua importância e o seu uso no processo de agregação de valor à empresa. Se em passado recente o cliente era tido como fonte de receita, hoje as empresas voltam-se para percebê-lo como parceiro, por intermédio do qual podem obter indícios, informações para a melhoria contínua de seus processos de trabalho, para a inovação e como elemento que pode agregar valor ao produto ${ }^{(3)}$.
Transpondo esses conceitos ao ramo de editoração de periódicos, este estudo se propõe a analisar o capital de relacionamento da Revista Latino-americana de Enfermagem (RLAE) e, através do mapeamento dos assinantes, checar o atendimento de objetivos da Revista, bem como identificar possibilidades e estratégias para melhoria e inovação nos processos de gestão.

\section{CARACTERIZAÇÃO DO PERIÓDICO EM ANÁLISE}

Os periódicos especializados surgiram no século XVII, resultantes da evolução natural de cartas, registros de reuniões e de comunicações particulares entre cientistas ${ }^{(4)}$.

O periódico científico objetiva manter informados os cientistas sobre os últimos acontecimentos e avanços em suas áreas. A contagem da publicação da literatura da pesquisa, dos artigos de periódicos, associada aos parâmetros de qualidade dos veículos usados, vem sendo utilizada como indicador de produtividade científica de nações, instituições, departamentos e indivíduos ${ }^{(5)}$.

A RLAE vem completar o compromisso da Escola de Enfermagem de Ribeirão Preto da Universidade de São Paulo (EERP/ USP) com o desenvolvimento da investigação científica, constituindo um veículo de comunicação do conhecimento produzido.

A designação da EERP/USP como Centro Colaborador da Organização Mundial da Saúde para o desenvolvimento da pesquisa em Enfermagem, em 1988, certamente contribuiu para a concretização desse veículo, que objetivou "a integração entre enfermeiros latinoamericanos para, através do conhecimento, tornar mais interrelacionada a enfermagem da região" ${ }^{(4)}$.

Lançada em 1993, tem por missão "promover a disseminação do conhecimento científico da enfermagem através da publicação arbitrada de artigos que contribuam para a expansão desta área do saber e para a fundamentação das ações profissionais"(6). Circulou semestralmente até 1995. A partir de 1996, somados aos fascículos regulares, editou números especiais ou extras. A periodicidade trimestral, mantendo-se a tática de publicação de números extras foi aplicada no período de 1998 a 2000. Desde 2001, a RLAE circula bimestralmente, não estando excluída a possibilidade de edição de fascículos especiais.

Em maio de 2003, totalizava 11 volumes editados, com 36 fascículos regulares e 8 números especiais. Registrava o recebimento de 1010 artigos, dentre os quais 588 artigos publicados; 98 artigos recusados; 76 artigos no prelo e 248 em análise.

Os artigos publicados são de autoria de enfermeiros e profissionais de áreas afins, oriundos de várias regiões do Brasil e de países como: Argentina, Chile, Colômbia, Cuba, Estados Unidos da América, Israel e Portugal.

Quanto aos recursos financeiros, em seu primeiro ano de 
circulação foi totalmente subvencionada pela Fundação Kellogg ${ }^{(7)}$, portanto sem qualquer ônus para os leitores. Do segundo ao quarto ano de edição, esse subsídio financeiro declinou gradualmente até a sua extinção.

Desde então, a RLAE concorre em programas de apoio à editoração na FAPESP - Fundação de Amparo à Pesquisa do Estado de São Paulo e no CNPq - Conselho Nacional de Pesquisa e Desenvolvimento. Os recursos captados cobrem parcialmente as despesas, sendo necessário o apoio orçamentário da própria EERP/ USP.

As modalidades de trabalho publicadas na RLAE são: artigos originais, revisões, atualizações, comunicações breves/relatos de casos, cartas ao editor, resenhas e página do estudante.

A RLAE apresenta a seguinte estrutura administrativa: Conselho Diretor, Comissão de Editoração, Conselho Editorial e secretaria. O Conselho Diretor é responsável pelos aspectos administrativo-financeiros, bem como pela determinação de políticas e diretrizes para editoração. À Comissão de Editoração cabe zelar pela qualidade técnico-científica da Revista, bem como divulgá-la junto ao público alvo. Apreciar a estrutura e o conteúdo científico das matérias destinadas à publicação, expedindo parecer sobre as mesmas é competência do Conselho Editorial que, em sua missão, conta com o auxílio de consultores ad hoc. O suporte técnico-administrativo é feito pela Seção de Comunicação Científica, vinculada à Assistência Técnica Acadêmica da EERP/USP.

A indexação da RLAE em bases de dados é uma das principais estratégias para ampliar sua visibilidade ${ }^{(8)}$. Em abril de 2003 , esta Revista estava cadastrada nas seguintes bases de dados: MEDLINE; LILACS - Literatura Latino-Americana e do Caribe em Ciências da Saúde; CAB HEALTH; CAB ABSTRACTS; CINAHL/ Cumulative Index to Nursing \& Allied Health Literature; ULRICH'S/ International Periodicals Directory; BDENF/Base de Dados em Enfermagem; PSYCINFO; CUIDEN.

Em 2001, a RLAE foi aprovada para integrar a coleção SciELO - Brasil ${ }^{(9)}$. A SciELO - Scientific Eletronic Library Online é uma biblioteca eletrônica que abrange uma coleção selecionada de periódicos científicos, especialmente desenvolvida para responder as necessidades da comunicação científica nos países em desenvolvimento e particularmente de países da América Latina e do Caribe.

A RLAE lidera as avaliações da Base Qualis dentre os periódicos nacionais de Enfermagem. Desde abril de 2001, integra a categoria "B" - periódicos de circulação internacional, sendo o único periódico nacional de enfermagem com tal classificação, dentre as 327 revistas científicas existentes na Base Qualis, em $2003^{(10)}$.

A concessão de apoio financeiro por agências de fomento, a aceitação da RLAE em bases de dados e, ainda, a classificação obtida na Base Qualis evidenciam conceitos positivos creditados à Revista.
Contudo, não há, até o momento, estudos focados nos assinantes da Revista, com a finalidade de averiguar o cumprimento de objetivos estratégicos desse periódico.

\section{OBJETIVO}

Analisar o capital de relacionamento e mapear os assinantes para verificação do atendimento aos objetivos estratégicos da RLAE: favorecer a integração entre enfermeiros do Brasil e daAmérica Latina e contribuir para a fundamentação das ações profissionais do enfermeiro para o avanço do ensino, da pesquisa e da assistência de enfermagem.

\section{METODOLOGIA}

Para execução deste estudo utilizou-se o banco de assinantes da RLAE. Até abril de 2003, o banco de assinantes contava com 785 registros, oferecendo as seguintes informações: nome, complemento, endereço completo, data de vencimento da assinatura, correio eletrônico do assinante, tipo de assinatura (mediante pagamento (A), doação (D) ou permuta $(P)$.

Aintegração entre enfermeiros do Brasil e da América Latina foi verificada através da penetração da RLAE, considerando a distribuição geográfica de assinantes, segundo o endereço de entrega da Revista. Todos os registros do banco de dados foram computados nesta fase do estudo. Primeiramente, os assinantes foram identificados segundo o país de origem. A seguir, dividiu-se os assinantes brasileiros de acordo com a unidade federativa a que pertencem.

Os resultados encontrados foram comparados a perfis mínimos considerados necessários para cumprimento do objetivo estratégico número um.

A segunda etapa constituiu-se de um estudo descritivo para avaliar se a RLAE tem contribuído, na visão do leitor, na fundamentação das ações profissionais do enfermeiro para o avanço do ensino, da pesquisa e da assistência de enfermagem. O instrumento utilizado foi um questionário validado por três juízes, cuja versão eletrônica privilegiou a adoção de um formato e de um aplicativo compatíveis com o maior número possível de browsers, além das diferentes configurações de hardware, a fim de maximizar a possibilidade de transmissão e recepção do instrumento com sucesso. Com a aprovação do Comitê de Ética em Pesquisa da EERP/USP, o questionário aplicado integrou sete perguntas sobre: formação profissional, grau de escolaridade, natureza da atividade profissional, local de trabalho, tempo de leitor e contribuição da RLAE nas ações profissionais, cabendo ao respondente assinalar uma única alternativa em cinco questões e duas outras possibilitavam múltipla escolha. 
Para aplicação do questionário, foram selecionados todos os assinantes categorizados como "pessoa física", totalizando 643 registros, dentre eles extraiu-se assinantes com correio eletrônico cadastrado, somando 550 sujeitos, aos quais foram remetidos os questionários eletrônicos.

\section{RESULTADOS}

Quanto à penetração, a RLAE possui 774 assinantes na América Latina (756 no Brasil, 1 naArgentina, 2 no Chile, 4 na Colômbia, 1 em Costa Rica, 1 em Cuba, 1 no Equador e 8 no México). Na América do Norte, possui 5 assinantes oriundos dos Estados Unidos da América. Na Europa, registra 6 assinantes (3 da Espanha, 1 da Inglaterra, 1 de Portugal e 1 do Reino Unido).

No território brasileiro, a Região Sudeste concentra 459 assinantes (13 do Espírito Santo, 50 de Minas Gerais, 53 do Rio de Janeiro e 343 de São Paulo). Na Região Sul, são 125 assinantes (55 no Paraná, 42 no Rio Grande do Sul e 28 em Santa Catarina). A Região Centro-Oeste totaliza 42 assinantes (11 no Distrito Federal, 12 em Goiás, 13 em Mato Grosso e 6 em Mato Grosso do Sul). A Região Nordeste soma 120 assinantes (7 em Alagoas, 20 na Bahia, 54 no Ceará, 2 no Maranhão, 9 na Paraíba, 8 em Pernambuco, 6 no Piauí e 2 em Sergipe. Distribuídos na Região Norte estão 10 assinantes (2 no Acre, 1 no Amapá, 4 no Pará, 1 em Rondônia e 2 no Tocantins).

A segunda parte do mapeamento dos assinantes da RLAE envolveu a remessa do questionário eletrônico a uma população com 550 sujeitos. Desses, 87 mensagens retornaram em virtude da não localização do usuário ou do servidor. Assim, foram entregues, com sucesso, 463 questionários. As respostas totalizaram 122, equivalentes à 26,3\% da população consultada.

Quanto à formação profissional, $100 \%$ dos respondentes afirmaram ser enfermeiros, sendo que 1 dos sujeitos acumula formação em psicologia.

O grau de escolaridade apontou a seguinte distribuição dos sujeitos: 62 com doutorado completo, 27 com doutorado incompleto, 24 com mestrado completo, 4 com mestrado incompleto, 1 superior completo, 1 com superior incompleto, 2 com especialização. Um dos sujeitos não assinalou sua resposta a essa pergunta. Nesta questão foram considerados apenas os graus obtidos através de cursos formais. Títulos obtidos através de concurso ou cargos da carreira docente não foram registrados.

Dentre os respondentes, 5 informaram ser portadores do título de livre-docente e 1 sujeito respondeu ocupar o cargo de professor titular. Essas 6 respostas foram lançadas na categoria "doutorado completo".

A distribuição dos respondentes segundo a natureza profissional pode ser visualizada na Tabela 1.
Tabela 1 - Distribuição dos assinantes da Revista Latino-americana de Enfermagem, segundo a natureza da atividade profissional, Ribeirão Preto -2003

\begin{tabular}{lc}
\hline \multicolumn{1}{c}{ Natureza da atividade } & Respondentes \\
\hline Professor universitário & 79 \\
Professor universitário/pesquisador & 04 \\
Professor universitário/enfermeiro & 12 \\
Professor universitário/pesquisador/enfermeiro & 01 \\
Professor universitário/professor de ensino médio & 01 \\
Professor universitário/professor de ensino médio/ & 01 \\
pesquisador & \\
Professor de ensino médio & 03 \\
Professor de ensino médio/organizador de curso & 01 \\
Professor de ensino médio/ pesquisador/enfermeiro & 01 \\
Pesquisador & 01 \\
Pesquisador/especialista de laboratório & 01 \\
Pesquisador/empresário & 01 \\
Pesquisador/assessor de pesquisa & 01 \\
Enfermeiro & 07 \\
Enfermeiro/pesquisador & 04 \\
Enfermeiro/pesquisador/professor & 01 \\
Especialista de laboratório & 01 \\
Estudante & 02 \\
\hline Total & 122 \\
\hline
\end{tabular}

Para esta questão foi prevista a possibilidade de mais de uma resposta. Dentre os respondentes, 24 sujeitos assinalaram as opções professor universitário e pesquisador. Ao cruzar essas respostas com as respostas atribuídas a questão 4 - seu local de trabalho, 20 sujeitos têm vínculo empregatício com instituições de ensino públicas.

Considerando que nas instituições de ensino superior públicas a pesquisa já está incluída no rol das atividades do professor universitário, optou-se, neste trabalho, em computar essas 20 respostas na categoria "professor universitário". Os 4 outros respondentes, por manterem vínculo empregatício com instituições de ensino privadas e não sendo possível identificar características das mesmas, optou-se por manter o registro "professor universitário/pesquisador". Amesma lógica foi aplicada aos respondentes que às atividades de professor universitário/pesquisador agregaram uma terceira atividade: Professor universitário/pesquisador/enfermeiro - 6 respondentes, 5 vinculados a instituições de ensino públicas, cujas respostas foram computadas na categoria "professor universitário/enfermeiro". Para o outro sujeito, vinculado a instituição de ensino privada, foi mantido o registro "professor universitário/pesquisador/enfermeiro". Semelhante princípio foi aplicado para 1 registro encontrado assinalando "professor universitário/pesquisador e professor de nível médio".

Quanto ao local de trabalho, 77 sujeitos estão em instituições de ensino públicas, 3 em instituições de ensino públicas e privadas, 6 em instituições de ensino públicas e instituições públicas de saúde, 19 em instituições de ensino privadas, 1 em instituição de ensino privada e instituição privada de saúde, 5 em instituições públicas de saúde, 1 em instituições pública e privada de saúde, 3 em instituições privadas de saúde, 1 em empresa, 1 em instituição militar e 1 sem vínculo, totalizando 121 respondentes. Um dos sujeitos não registrou sua resposta a essa questão.

Indagados quanto ao tempo de assinatura da RLAE, os 
respondentes distribuem-se em: 14 com até 1 ano de assinatura, 8 com 2 anos de assinatura, 13 com 3 anos de assinatura, 10 com 4 anos de assinatura, 8 com 5 anos de assinatura, 7 com 6 anos de assinatura, 11 com 7 anos de assinatura, 10 com 8 anos de assinatura, 5 com 9 anos de assinatura e 36 com 10 anos de assinatura.

Sobre a contribuição da RLAE para a fundamentação de suas ações profissionais, 119 sujeitos responderam afirmativamente, 1 sujeito negativamente e 2 sujeitos assinalaram a opção indiferente.

Dentre as respostas afirmativas, os sujeitos informaram em uma escala de 1 a 10 o grau de contribuição da RLAE em suas atividades profissionais, sendo 100 valor máximo de contribuição. Foram obtidas as seguintes respostas: grau 2 para 1 sujeito, grau 3 para 2 sujeitos, grau 4 para 5 sujeitos, grau 5 para 12 sujeitos, grau 6 para 10 sujeitos, grau 7 para 23 sujeitos, grau 8 para 30 sujeitos, grau 9 para 23 sujeitos e grau 10 para 12 sujeitos. Nenhum respondente assinalou a opção grau 1.

Um dos sujeitos, em que pese ter respondido afirmativamente na questão de número 6 (se a RLAE contribui para a fundamentação de suas ações profissionais), não assinalou sua resposta na pergunta número 7. Pela configuração assumida no retorno do questionário, há sinais contundentes de problemas de software, que impediram a leitura dessa resposta.

\section{ANÁLISE DOS RESULTADOS}

Os leitores potenciais da RLAE podem ser divididos em quatro grandes categorias: 1) enfermeiros voltados à docência e/ou à pesquisa; 2) enfermeiros prestadores de assistência autônomos ou vinculados a instituições de saúde, clínicas e similares, empresas, Forças Armadas, etc; 3) enfermeiros atuantes em segmentos correlatos, como por exemplo na área comercial de laboratórios e indústrias de produtos e equipamentos médico-hospitalares, em instâncias governamentais participando da elaboração, aplicação e gerenciamento de políticas públicas de saúde e 4) outros profissionais de áreas afins.

Neste estudo, a integração entre enfermeiros do Brasil e da América Latina é dimensionada a partir da penetração da RLAE nas unidades federativas do Brasil e nos países latino-americanos.

A linha editorial da RLAE privilegia a divulgação de resultados de pesquisas inéditas. No Brasil, esse padrão de literatura científica é consumido, majoritariamente, por professores/pesquisadores de instituições de ensino superior, seguidos de enfermeiros interessados em pesquisa, normalmente vinculados a hospitais que valorizam a atividade científica ou por motivação pessoal. Partindo-se desta premissa, a RLAE deve focar sua penetração na América Latina, primeiramente, através de instituições de ensino superior e que adicionalmente sejam mantenedoras de cursos de pós-graduação stricto sensu, demonstrando, portanto, vocação para a investigação científica.

Em recente pesquisa desenvolvida a pedido da Organização dos Estados Americanos - Comissão Interamericana para o Controle do Abuso de Drogas (OEA-CICAD) ${ }^{(11)}$, mapeou-se os países latinoamericanos com mestrados e doutorados em enfermagem. O Brasil mereceu estudo individualizado estando, nessa área, avançado em relação aos demais países daAmérica Latina. Essa pesquisa identificou 26 universidades mantenedoras de cursos de pós-graduação stricto sensu em enfermagem, instaladas em 7 países daAmérica Latina, além do Brasil. Esses cursos distribuem-se assim: 2 cursos de doutorado na Argentina, 1 curso de mestrado e 1 curso de doutorado no Chile, 4 cursos de mestrado e 1 curso de doutorado na Colômbia, 3 cursos de mestrado no Equador, 11 cursos de mestrado e 1 curso de doutorado no México, 4 cursos de mestrado no Peru e 2 cursos mestrado e 1 curso de doutorado na Venezuela. Dos 6 cursos de doutorado arrolados, 3 estavam em funcionamento no ano de $2002 \mathrm{e}$ os demais com perspectivas de início em $2003^{(11)}$.

Identificou-se, ainda, a existência de 2 cursos de mestrado na Argentina, não sendo possível vinculá-los a(s) universidade(s) de origem. O mesmo ocorreu em relação a Bolívia, verificando-se a existência de um mestrado naquele país.

Constatou-se que a RLAE está presente em 7 países da América Latina, além do Brasil, a saber: Argentina(1); Chile(2); Colômbia (4); Costa Rica(1); Cuba(1); Equador(1) e México(8), totalizando 18 assinantes. Desses, 3 são assinaturas feitas por instituições de ensino; 5 são permutas com periódicos e 1 assinatura pertence à Associação Latino-americana de Escolas e Faculdades de Enfermagem ALADEFE. Das 9 assinaturas institucionais apenas duas pertencem a instituições identificadas na pesquisa mencionada. Os outros 9 assinantes oriundos da América Latina são de natureza jurídica categorizada como "pessoa física".

Com base no perfil de cliente institucional da RLAE estabelecido neste estudo e nos números identificados de assinaturas institucionais e pessoa física é possível concluir que a Revista Latinoamericana de Enfermagem, em seus 10 anos, atingiu uma penetração incipiente nos países da América Latina que, com exceção do Brasil, possuem poucas e recentes opções de doutorado, o que influencia diretamente na formação de pesquisadores e consumidores de pesquisa.

À distribuição da RLAE no Brasil se aplica a premissa anteriormente citada quanto ao perfil do assinante institucional da Revista. Por conseguinte, a Revista deve estar presente no acervo das instituições de ensino superior, priorizando-se aquelas que oferecem cursos de pós-graduação stricto sensu. Os hospitais-escola mantenedores de residência em enfermagem e outras modalidades de ensino também representam uma vertente importante de assinantes, 
compondo com as escolas e faculdades de enfermagem a classe de leitores formadores de opinião.

A distribuição da RLAE em faculdades de enfermagem, atuantes exclusiva ou prioritariamente no campo da graduação, pode ser ordenada utilizando-se os conceitos de avaliação de cursos de enfermagem, disponibilizados pelo Ministério da Educação e Cultura.

Até 2002, funcionavam no Brasil 21 programas de pósgraduação stricto sensu reconhecidos pela CAPES, totalizando 20 cursos de mestrado e 8 cursos de doutorado, assim distribuídos: Região Sudeste - 12 programas instalados em 7 universidades, com 11 mestrados e 7 doutorados; Região Sul - 4 programas instalados em 4 universidades, com 4 mestrados e 1 doutorado; Região Nordeste - 4 programas instalados em 4 universidades, com 4 mestrados e 1 doutorado.

Com base no cadastro do INEP Instituto Nacional de Estudos e Pesquisas Educacionais "Anísio Teixeira"(12), em maio de 2003 somavam, no Brasil, 352 cursos de enfermagem, assim distribuídos: Região Norte - 23; Região Nordeste - 50; Região Centro-Oeste - 25; Região Sudeste - 180; Região Sul - 74. Na apresentação do INEP não há como aferir o total de cursos avaliados dentro da enfermagem. As instituições de ensino avaliadas em 2002 totalizam 133 assim distribuídas: Região Norte - 7; Região Nordeste - 25; Região Centro-Oeste - 7; Região Sudeste - 63; Região Sul - 31.

A RLAE está presente em 25 unidades federativas, não tendo assinantes, em maio de 2003, apenas nos estados do Amazonas e Roraima, cabendo registrar que em Roraima inexiste curso de graduação em Enfermagem.

Resgatando o perfil de clientes institucionais e confrontando os números levantados nesta pesquisa, verifica-se que são assinantes da RLAE 118 instituições de ensino, correspondente a 33,5\% do universo de cursos de graduação em enfermagem cadastrados no INEP. Compõem, ainda, o banco de assinantes, dentre esses clientes institucionais, $62 \%$ dos programas de pós-graduação stricto sensu. De instituições de saúde aparecem apenas 4 registros.

Nota-se, também, a concentração de assinantes da RLAE na Região Sudeste, coincidindo com a concentração de instituições de ensino que oferecem cursos de graduação em enfermagem.

As assinaturas institucionais são importantes porque possibilitam o acesso à Revista de um maior contingente de leitores. Além de disseminar o conhecimento e favorecer a integração de enfermeiros e a fundamentação de ações profissionais, espera-se que o contato do leitor com a Revista fomente a realização de assinaturas individuais e seja um estímulo à submissão de trabalhos científicos para publicação na mesma.

Os resultados encontrados permitem concluir que a Revista Latino-americana de Enfermagem vem contribuindo para a integração dos enfermeiros do Brasil, uma vez que está disseminada em 92,5\% do território nacional. Ressalte-se, ainda, a larga fatia de mercado a ser explorada pela Revista, com vistas a ampliar esse capital de relacionamento.

A verificação do atendimento do segundo objetivo estratégico da RLAE, qual seja: "contribuir para a fundamentação das ações profissionais do enfermeiro para o avanço do ensino, da pesquisa e da assistência de enfermagem", foi feita através de questionário eletrônico enviado a 550 assinantes, obtendo-se 122 respostas.

As 4 primeiras questões permitem a caracterização do assinante quanto a sua formação profissional, escolaridade, natureza e local da atividade profissional. Dentre os respondentes, 100\% revelaram ser enfermeiros, um dos quais com formação também em psicologia. Quanto à escolaridade, 50,8\% são detentores do título de doutor; 22\% realizam curso de doutorado; 19,7\% têm mestrado completo; 3,3\% cursam mestrado; 1,6\% possui título de especialista. Isto equivale a dizer que 119 respondentes - 98,3\%, têm curso de pósgraduação. Quanto aos 2 outros sujeitos, 1 concluiu o curso de graduação e 1 não tem o curso de graduação completo. No que se refere à atividade profissional, 80,3\% dos respondentes revelaram exercer a docência no ensino superior. A docência, como atividade exclusiva, foi assinalada por $64,7 \%$ dos respondentes e com outras atividades agregadas (pesquisador, enfermeiro, professor de nível médio), 15,6\%, dentre esses sujeitos. A opção "Enfermeiro" aparece em $9,8 \%$ das respostas. Como atividade exclusiva, correspondente a $5,7 \%$ e associada a outras atividades (pesquisador e professor, excetuando-se professor universitário e professor de ensino médio), $4,1 \%$ dentre os respondentes. Professor de ensino médio foi assinalado por 4,1\% dos respondentes, sendo 2,5\% como atividade exclusiva e 1,6\% com outras atividades agregadas (organizador de curso, pesquisador e enfermeiro). Pesquisador, pesquisador/especialista de laboratório, pesquisador/empresário e pesquisador/assessor de pesquisa representam 3,3\% das respostas. A opção "Estudante" foi assinalada por 1,6\% dos respondentes; também há registro de 1 especialista de laboratório, equivalendo a 0,8\% dos sujeitos.

Quanto ao local de trabalho, a predominância está na opção instituição de ensino pública, com $71 \%$ das respostas, entre as quais 63,6\% correspondem à opção única e 7,4\%, instituição de ensino pública associada a outros locais (instituição de ensino privada, instituição pública de saúde). Na seqüência surgem as instituições de ensino privadas, com $19 \%$ das respostas, sendo que $15,7 \%$ das respostas apontam essa opção isolada e 3,3\% associam com outros locais de trabalho (instituição pública de saúde, instituição privada de saúde). A instituição pública de saúde, como único local de trabalho, totaliza 4,1\% das respostas. Agregada a outro local (instituição privada de saúde), soma mais 0,8\%. A opção instituição privada de saúde, isoladamente, foi assinalada por $2,6 \%$ dos respondentes. Outras opções como empresa e instituição militar totalizam 1,6\% das respostas. Sem 
vínculo empregatício foi assinalado por 1 sujeito, equivalendo a 0,8\% das respostas.

Nessas respostas, percebe-se a predominância de leitores enfermeiros, com atividade profissional voltada para a docência e em instituições de ensino públicas e privadas. Esse perfil coaduna-se com a linha editorial da RLAE.

A quinta questão foi direcionada para conhecer o tempo do relacionamento do cliente com a Revista, através da assinatura.

Tomando em conta o tempo de existência da RLAE - 10 anos, para fins deste estudo definiu-se que um cliente fidelizado é aquele que assina a Revista há no mínimo 7 anos; em fase de fidelização estão os assinantes na linha de 4 a 6 anos; e os novos clientes são compostos por assinantes com até 3 anos.

Aplicando-se esse critério, verifica-se 62 respondentes no grupo de clientes fidelizados (51\%); 25 no grupo de clientes em fase de fidelização (20\%) e 35 no grupo de clientes classificados como novos assinantes (29\%).

Por se tratar de um estudo descritivo e considerando que 0 total de respondentes corresponde a 19\% do total de assinantes da Revista na categoria de pessoa física, o resultado espelhado não pode ser estendido a todos os assinantes. Porém, é preciso que as instâncias gestoras da RLAE tenham em mente a distribuição de clientes segundo a etapa de fidelização, a fim de que possam elaborar estratégias adequadas de relacionamento.

Na execução deste trabalho identificou-se a inexistência de sistema de acompanhamento do assinante. O banco de dados atualmente disponível acusa apenas a vigência da assinatura, não registrando a trajetória do cliente em renovações, interstícios ou a introdução de novos assinantes. Perde-se, portanto, uma importante informação para um trabalho de marketing, partindo-se do princípio que clientes em diferentes fases de relacionamento com o produto devem merecer abordagens distintas, com vistas a migração e manutenção na categoria "clientes fidelizados".

As questões 6 e 7 abordam, diretamente, a contribuição da RLAE para a fundamentação das ações profissionais - fulcro do segundo objetivo estratégico.

Os resultados evidenciam que 97,5\% dos respondentes (119 sujeitos) afirmam que a Revista contribui para a fundamentação de suas ações profissionais, 1 sujeito respondeu negativamente e 2 outros assinalaram a opção indiferente.

Na seqüência, os 118 sujeitos informaram numa escala de 0 a 10 o grau de contribuição da Revista para sua prática profissional.

\section{REFERÊNCIAS BIBLIOGRÁFICAS}

1. Gordon C. Posfácio. In: Terra, JCC. Gestão do conhecimento: 0 grande desafio empresarial: uma abordagem baseada no aprendizado e na criatividade. São Paulo (SP): Negócio Editora; 2000.
Para fins deste trabalho, à escala foram aplicados os seguintes conceitos: de 1 a 3 - pouco (contribuição reduzida), de 4 a 5 - regular (contribuição mediana), de 6 a 7 - satisfatório (contribuição suficiente), de 8 a 10 muito (grande contribuição).

Assim, 65 sujeitos enquadram-se no conceito máximo de contribuição (55\%), 33 sujeitos (28\%) consideram satisfatória a contribuição da RLAE para sua prática profissional, 17 respondentes (14\%) afirmam que a contribuição é regular e 3 (3\%) sujeitos informam pouca contribuição da RLAE em suas ações profissionais.

Diante do exposto, segundo os respondentes, a Revista Latino-americana de Enfermagem vem cumprindo com o seu objetivo de "contribuir para a fundamentação das ações profissionais do enfermeiro para o avanço do ensino, da pesquisa e da assistência de enfermagem", e de forma bastante intensa, já que $55 \%$ dos sujeitos concentram-se entre os graus 8 a 10 na escala proposta.

\section{CONSIDERAÇÕES FINAIS}

Compuseram a população deste estudo 550 dos 643 assinantes da RLAE categorizados como "pessoa física" e o número de respondentes foi de 122, portanto, 19\% da categoria de assinantes "pessoa física". Dentre os respondentes, a predominância é de enfermeiros com atividades profissionais voltadas para a docência em instituições de ensino de nível superior $(64,7 \%)$, mas a pesquisa não permite concluir se, de fato, a participação de enfermeiros prestadores de assistência à saúde limita-se a 5,7\% ou mantém a proporção verificada nas respostas (11 professores universitários para cada 1 enfermeiro).

Retornando à verificação do atendimento ao primeiro objetivo estratégico da RLAE: "favorecer a integração entre enfermeiros do Brasil e da América Latina para, através do conhecimento, tornar mais inter-relacionada a enfermagem da Região" ${ }^{\prime(4)}$, verificou-se que ainda é incipiente a penetração da Revista na América Latina e que no Brasil é satisfatória.

A fundamentação das ações profissionais do enfermeiro para 0 avanço do ensino, da pesquisa e da assistência de enfermagem, segundo objetivo estratégico da Revista, foi confirmada pelos respondentes da pesquisa.

O presente estudo reuniu, ainda, outros indicadores para a gestão da Revista, que poderão determinar ações para melhorias e inovações nos processos administrativos, financeiros e mercadológicos.

2. Pezzo M. Sociedade da Informação. Univerciência 2003 maio; 4:49.

3. Cavalcanti M, Gomes EBP, Pereira AF Neto. Gestão de empresas na sociedade do conhecimento: um roteiro para a ação. Rio de Janeiro (RJ): Campus; 2001. 
4. Mendes IAC. Carta ao leitor. Rev Latino-am Enfermagem 1993 janeiro; 1(1):7-8.

5. Souza EP, Paula MCS. QUALIS: a base de qualificação dos periódicos científicos utilizada na avaliação CAPES. Infocapes 2002 abril/junho; 10(2):7-25.

6. Scientific Eletronic Library OnLine. SciELO. [página na Internet]. São Paulo: SciELO; FAPESP; BIREME; c 2005. [update march 09, 2005; acesso 28 de setembro 2002]. Disponível em: http:Ilwww.scielo.br/scielo.php?script=sci_issuetoc\&pid=0104116920020004\&lng=en\&nrm=iso.

7. Conselho Diretor da Revista Latino-americana de Enfermagem. Relatório Científico 1993-1998. Ribeirão Preto (SP): EERP/USP; 1999. 8. Marziale MHP, Mendes IAC. Dez anos contribuindo para a memória da ciência: Revista Latino-americana de Enfermagem. Rev Latino-am Enfermagem 2003 março; 11(2):143-5.

9. Marziale MHP, Mendes IAC. Uma grande conquista: Revista Latinoamericana de Enfermagem na coleção SciELO. Rev Latino-am Enfermagem 2002 janeiro; 10(1):1-2.

10. Coordenação de Aperfeiçoamento de Pessoal de Nível Superior. CAPES [página na Internet]. Brasília: CAPES. c 2005. [atualização 15 de março 2005; citado em novembro de 2004]. Disponível em: http:llwww.capes.gov.br.

11. Comisión Inter-americana para el Control Del Abuso de Drogas/ CICAD. La situación de los programas de postgrado de enfermería en nueve países de América Latina frente a los desafios de la reducción de la demanda de drogas. Washington, D.C.; Florianópolis: UFSC/ PEN; 2003.

12. INEP. Instituto Nacional de Estudos e Pesquisas Educacionais "Anísio Teixeira". [página na Internet]. Brasília: INEP. [citado em maio 2003]. Disponível em: http://www.inep.gov.br. 